\title{
Crisis behaviors as drivers of value co-creation transformation
}

\author{
Bo Edvardsson \\ Service Research Center, Karlstad University, Karlstad, Sweden and Inland \\ Norway University of Applied Sciences, Elverum, Norway, and \\ Bård Tronvoll \\ Inland Norway University of Applied Sciences, Elverum, Norway and \\ CTF - Service Research Center, Karlstad University, Karlstad, Sweden
}

Drivers of
value co-
creation
transformation

Received 1 January 2021

Revised 27 March 2021

Accepted 27 March 2021

\begin{abstract}
Purpose - The paper aims to conceptualize how behavioral shifts in times of crisis drive the transformation of value co-creation.

Design/methodology/approach - Referencing two empirical contexts, the paper explores how digital service platforms facilitate changes in actors' mental models and institutional arrangements (legal, social, technological) that drive transformation of value co-creation in service ecosystems.

Findings - The proposed conceptual framework contributes to existing research by identifying micro-level changes in actors' mental models and macro-level changes in institutional arrangements enabled by digital service platforms in service ecosystems. In particular, the framework identifies motivation, agility and resistance as moderators of behavioral shifts in times of crisis. This account offers a finer-grained theorization of the moderating factors and underlying mechanisms of service ecosystem transformation but does not extend to the ensuing "new normal."

Practical implications - The proposed framework indicates how digital platforms support shifts in actors' behavior and contribute to the transformation of value co-creation. While the enablers are situation-specific and may therefore vary according to the prevailing conditions, the actor-related concepts advanced here seem likely to remain relevant when analyzing the transformation of value co-creation in other crisis situations.

Originality/value - The new conceptual framework advanced here clarifies how behavioral shifts during a crisis drive the transformation of value co-creation and suggests directions for future research.
\end{abstract}

Keywords Transformation, Fear, Mental model, Service ecosystem, Crisis, Institutional arrangements, Behavior shift, Digital service platform

Paper type Research paper

\section{Introduction}

Rapid change in markets and societies is reflected in the changing behaviors of customers, firms and other actors. In the service and marketing literature, the extensive research on consumer behavior (Belk et al., 2012; Jagtap and Deshmukh, 2018) can be categorized in terms of three broad explanatory approaches (Valaskova et al., 2015): the psychology of consumer behavior; the sociology of consumer reactions in different situations; and the economic approach, which explains consumer requirements and behaviors in terms of

(C) Bo Edvardsson and Bård Tronvoll. Published by Emerald Publishing Limited. This article is published under the Creative Commons Attribution (CC BY 4.0) licence. Anyone may reproduce, distribute, translate and create derivative works of this article (for both commercial and noncommercial purposes), subject to full attribution to the original publication and authors. The full terms of this licence maybe seen at http://creativecommons.org/licences/by/4.0/legalcode

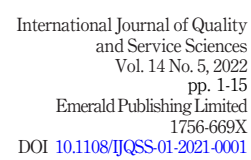


IJQSS

14,5

market knowledge and the processes of exchange. While Shvo et al. (2020, p. 137) have argued for the need to analyze changing customer values, goals and technologies to understand "behavior change to come," most previous research has focused on voluntary or desired behavioral change.

Psychologists have emphasized the dynamic and psychosocial drivers of voluntary behavior change (Kappas, 2013; Littell and Girvin, 2002), citing environmental, personal and behavioral characteristics as key factors (Lange et al., 2012). Some recent studies distinguish between models of behavior and theories of change (van der Linden, 2013); while the former seek to explain a given behavior, the latter address behavioral change. The present paper advances a conceptual framework to clarify the nature of involuntary change in times of crisis, characterized here as behavioral shift. Crises force actors to change their behavior rapidly and fundamentally (Baker et al., 2015) as a necessary response to changing circumstances (Bundy et al., 2017). When actors shift their behavior more or less simultaneously, one effect is the transformation of value co-creation in service ecosystems. To explain these significant involuntary behavioral shifts, it is essential to understand the entire process of transformation, including its cognitive, affective and behavioral aspects. This transformation involves crisis recognition and response phases that reflect the actor's ability to absorb the initial shock and changes in behavior that are typically driven by uncertainty and fear in adapting to a new reality. To understand why actors behave as they do in crisis contexts, it is essential to understand these initial responses and the factors that drive behavior change. According to Koskela-Huotari et al. (2016), a crisis situation fuels transformation of value co-creation as service ecosystem actors adjust to new roles and situations in pursuit of beneficial outcomes.

Rather than drawing on primary data, the arguments developed here assimilate and combine existing concepts and theories (Hirschheim, 2008). Jaakkola (2020) identified two possible points of departure for conceptual papers of this kind. One option is to address a neglected aspect of the focal phenomenon through inductive identification of the concepts or theories that inform differing conceptualizations. The present paper focuses on the behavioral shifts that drive the transformation of value co-creation in service ecosystems during times of crisis - in this case, the COVID-19 pandemic. The paper explores how digital service platforms facilitate changes in actors' mental models and legal, social, technological and other institutional arrangements that drive the transformation of value co-creation in service ecosystems. For present purposes, that transformation is defined as a significant change in relevant actors' use of their knowledge and skills to integrate resources for value co-creation during a crisis (see e.g. Vargo and Lusch, 2004, 2016).

The proposed conceptual framework contributes to existing research on value cocreation by showing how micro-level changes in the mental models of individual actors and macro-level changes in institutional arrangements are enabled at meso level by digital service platforms in service ecosystems. In particular, the framework accounts for the role of motivation, agility and resistance as moderators of change. The paper provides a finergrained theoretical understanding of the moderating factors and underlying mechanisms of change beyond self-adjustment during crisis situations. Examples from the retail and education sectors briefly illustrate the framework's empirical application, and the paper concludes with some suggestions for future research.

\section{Conceptual background and framing}

The term crisis applies to any situation characterized by intense anxiety, fear and psychological stress when making decisions (Bundy et al., 2017) at every level - individual, organizational, societal and sometimes global. As an extreme case of change, the disruptive 
effects of a crisis include uncertainty, fear, confusion and intense dread (Barton, 2008; Borodzicz, 2005). While these feelings can motivate appropriate action beyond what is generally accepted as everyday behavior, anxiety and fear of the unknown may also discourage such actions (Fernandes, 2020). In times of crisis, actors must rapidly adjust their behavior (Coombs, 2007), resulting in value co-creation transformation. However, because crises are complex and unpredictable, actors' concerns are often ambiguous (Wooten and James, 2008), as significant, abrupt and often damaging change impacts individual security. As well as threatening health and safety, economic, political, societal and environmental upheaval (Rasoulinezhad, 2012) means the potential loss of financial assets and possessions that underpin value co-creation, requiring radical behavioral shifts to adapt to rapid change. In the marketing literature, Baker et al. (2007) argued that these shifts may be experienced as a social process - a state of flux in which individuals and social groups strive actively and constructively to move beyond their vulnerable state. As a "relatively self-contained, selfadjusting system of resource-integrating actors connected by shared institutional arrangements and mutual value creation through service exchange" (Lusch and Vargo, 2014, p. 11), service ecosystems are forced to self-adjust in times of crisis (Vargo and Lusch, 2004, 2016), driving the transformation of value co-creation.

Behavioral shifts during a crisis can be conceptualized in terms of altered mental models and institutional arrangements. Mental models - assumptions about how the world works guide our behavior and how we interpret our environment (Vink et al., 2019). As an internal compass that informs cognition, reasoning, decision-making and coping strategies, mental models guide how the individual thinks about how things work in the real world (Baron, 2006). Grounded in life experience and social, ethical and economic values, our mental models shape us and our behavior (Senge et al., 2011) by determining our beliefs about social reality and appropriate action. As such, they are crucial at times of crisis as heuristics grounded in past experience that help to reduce uncertainty (Prahalad and Bettis, 1986) in preparing for purposeful action. It follows that we can change our thinking and behavior by becoming more aware of our mental models.

Changes in mental models are reinforced by simultaneous changes in institutional arrangements, including rules about how society works and what is legally and socially acceptable. Institutional arrangements are the norms, beliefs, rules and habits that maintain the social order and coordinate the behavior of multiple individuals within a given group or society (Miller, 2014). According to Scott (2008), the role of institutions is to provide guidelines and resources for action and prohibit or constrain specified activities and interactions; among these, institutions specify the "rules of the game" for value co-creation in service ecosystems, including both formal constraints like regulations and laws and less formal constraints such as the norms and conventions that all actors produce and reproduce (North, 1990, p. 4). During the COVID-19 crisis, digital service platforms have enabled changes in mental models and institutional arrangements that enhance access to resources and facilitate collaboration (Edvardsson and Tronvoll, 2020). By simultaneously accommodating human interaction and social distancing, digital service platforms have enabled individuals, firms and government agencies to maintain essential activities during the pandemic, including remote working and delivery of health-care and education services. Digital service platforms facilitate everyday service exchanges (Lusch and Nambisan, 2015) by moving them online. Beyond their convenience and efficiency, these platforms play an indispensable role in maintaining social and physical distancing by transforming value cocreation in service ecosystems.

During a crisis, the anxiety, fear and uncertainty triggered by deviations from normal behavior and everyday routines (Feldman et al., 2012) also reduce resistance to change.
Drivers of value cocreation transformation 
IJQSS

14,5

The focus and pace of behavioral shifts (in normal circumstances as well as in times of crisis) is in part determined by the so-called MAR factors: motivation, agility and resistance (Edwards and Lambert, 2007). Motivation determines the individual's energy and enthusiasm when engaging in certain activities to achieve desired goals; this has an objective aspect (the desired goal or outcome) and a subjective aspect (the emotions to be resolved, such as anxiety and fear during a crisis). For present purposes, emotions are understood as automatic judgments based on unconscious values and beliefs invested in an object, outcome or response. As the psychological process that underpins intention and drives behavior, motivation largely accounts for why individuals behave as they do, not least in times of crisis.

According to motivation theorists, these internal and external factors impel or suppress action (Locke and Latham, 2004), affecting the direction (choice), intensity (effort) and duration (persistence) of an activity or behavior (Pinder, 2008). As a set of forces originating both within and outside the individual, motivation also drives value co-creation and determines its form, direction, intensity and duration (Findsrud et al., 2018). In times of crisis, emotions as well as changing beliefs and values can affect an actor's motivation (Locke, 2009). Most social psychological theories explain behavior change as the conversion of emotions and motives into action. On this view, the sense of urgency created by a crisis can generate anxiety, which may be transformative (Kotter, 2008), as actors strive to reduce their vulnerability, so confirming the key role of motivation in behavioral change.

A second moderator of behavioral change is agility - the ability to adjust quickly and easily (Dove, 2002) to achieve stability in a turbulent environment (Orlov, 2017). Agile actors can respond quickly to opportunities or threats, whether internal (e.g. procedural) or external (e.g. legal or environmental) if they have a stable foundation or platform. As a first requirement, agility depends on a willingness to adjust existing mental models. An agile mindset also involves trusting other individuals (e.g. family, friends, neighbors) or government agencies (e.g. disease control centers, central and local authorities) to respond appropriately to the crisis (Rigby et al., 2018). This ability to cope with profound uncertainty and act differently is known as agile transformation (Naslund and Kale, 2020); in a crisis, agile thinking and behavior is vital, empowering actors to be flexible and to embrace change rather than resisting it (Williams and Cockburn, 2003).

The third moderator of behavioral change is resistance, which refers to actors' tendency to reject change when they are unable to accommodate the new behaviors that a crisis demands (Bovey and Hede, 2001). This applies to a wide range of actions and behaviors in diverse contexts and at all levels of individual and social life, including political systems and the workplace (Hollander and Einwohner, 2004). Resistance to change can be defined as "any conduct that serves to maintain the status quo in the face of pressure to alter the status quo" (Duncan and Zaltman, 1977, p. 63). As a period of disruptive change, responses to a crisis can be said to involve three phases of change that relate to threat perception: unfreezing, moving and refreezing (Lewin, 1951). Individuals feel most threatened and resistant to change during the unfreezing stage, when the status quo is altered - for example, when implementing new procedures or modifying embedded routines (Busco et al., 2006). However, the effect can be reduced by an acceptable process and the prospect of a favorable outcome.

Resistance has also been framed as a transformative act involving cognitive and behavioral change (Haaland and Wallevik, 2019). Driven by anxiety and fear, a cognitive shift emphasizing cooperation rather than competition can reduce resistance to change in a time of crisis (Bovey and Hede, 2001; Chreim, 2002). During the COVID-19 pandemic, social sanctions based on the prospect of illness or death, as well as a positive vision of a virus-free 
society, may potentially reduce or eliminate resistance to behavioral change. Driven by urgent need and an acceptance that everyone can contribute through collaboration (Roozenbeek and van der Linden, 2019), that change is more likely to be natural and enduring. Figure 1 shows how changes, enablers and moderators combine to explain the shift from everyday behavior to crisis behavior.

Figure 1 conceptualizes how the shift from normal pre-crisis behavior to crisis behavior drives the transformation of value co-creation, highlighting the role of individual mental models and the influence of the three interdependent MAR moderators. Beyond the microlevel, the framework also captures the effects on behavior of upward and downward causality and moderating factors at the meso and macro levels (Capra and Luisi, 2014). Interactions among the MAR factors reinforce or weaken these effects by influencing mental models and institutional arrangements, lending energy and direction to behavioral shifts. This explains how digital service platforms enable and drive the transformation of value cocreation in service ecosystems and in society at large. However, changes in value co-creation would be slower without access to an enabler; in the context of the COVID-19 crisis, that enabler is the digital service platform.

\section{From pre-crisis to crisis behavior: changes in value co-creation}

The role of behavioral shifts and new institutional arrangements (Siltaloppi et al., 2016) in the transformation of value co-creation (Ramaswamy, 2009) has been confirmed by existing research on transformative service (Anderson et al., 2013), transformative service design (Sangiorgi, 2011) and digital service transformation (Lusch and Nambisan, 2015). According to Belenky and Stanton (2000), transformation is a result of changes in knowing and learning. Manna et al. (2018) argued that institutionalized practices shape the transformation of value co-creation in service ecosystems by redefining actors' roles and resource integration techniques, fundamentally altering activities, resources, behaviors and mindsets.

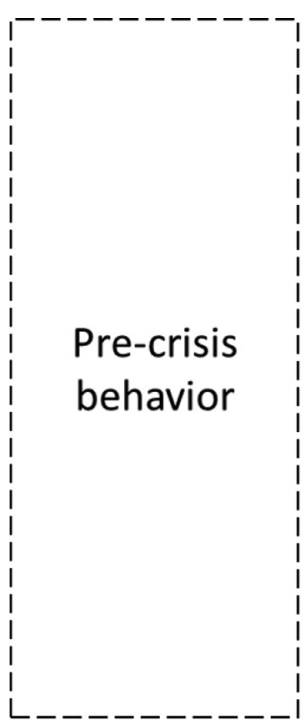

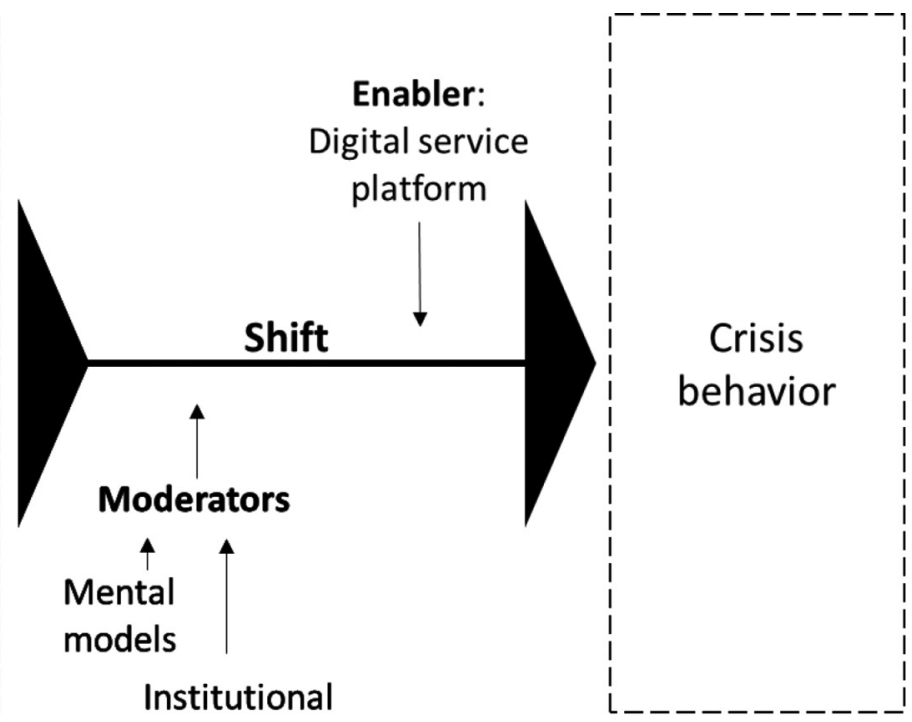

Drivers of value cocreation transformation
Figure 1.

The shift from precrisis to crisis behavior 
IJQSS

14,5

In the proposed conceptual framework, the digital service platform is the main enabler of transformative shifts in behavior (Barile et al., 2017). Verhoef et al. (2019) showed how digitally enabled transformation of value co-creation fundamentally alters customer behaviors, requiring firms to change their business models. Broekhuizen et al. (2019) proposed that platforms facilitate transformation and ensure favorable business outcomes when it becomes a strategic priority. Even before the COVID-19 pandemic, most organizations had recognized that digital service platforms enhanced co-creation of value and growth. As it becomes easier to digitize value co-creation processes, these platforms are transforming service ecosystems and society at large. The COVID-19 pandemic has accelerated this change, as many employees have had to self-isolate or work from home, and online shopping, healthcare, conferencing, and teaching have increasingly become the "new normal."

The conceptual framework elaborated here seeks to explain the transformation of value co-creation during times of crisis by highlighting behavior shifts grounded in changing mental models and institutional arrangements. Value is always co-created and assessed in use contexts, including social contexts (Edvardsson et al., 2011; Vargo and Lusch, 2008), embedded in and shaped by the service ecosystem (Bettencourt et al., 2014); in the present case, the use context is value-in-crisis.

\section{Some empirical illustrations}

In a crisis, resource integration must change, guiding the actor to reassess value-in-context. Subsequent changes in mental models and the institutional arrangements that coordinate resource integration inform shifts in crisis behavior, driving the transformation of value cocreation (Ramaswamy, 2009). For present purposes, empirical examples from the education and retail service ecosystems serve to illustrate how value co-creation has been transformed during the COVID-19 crisis. We go on to show how the proposed framework helps to account for such changes during two other crises: the global financial crisis of 2008-2009 and the Thailand tsunami in 2004.

According to the United Nations, "The COVID-19 pandemic has created the largest transformation of education systems in history, affecting nearly 1.6 billion learners in more than 190 countries and all continents. Closures of schools and other learning spaces have impacted $94 \%$ of the world's student population, up to $99 \%$ in low and lower-middle-income countries" (2020, p. 2). In effect, the crisis has stimulated innovation and change in the education service ecosystem, including rapid-response distance-learning solutions developed by governments and partners worldwide to maintain learning continuity. At the height of the crisis, the university classroom transitioned from on-campus to platformdriven digital learning - in some cases within $48 \mathrm{~h}$. Students and academic and administrative staff were banned from classrooms and offices, and security personnel guarded entrances. This rapid transition to digital communication and platform-based learning included all university examinations and course-related activities, representing a significant change in how learning is delivered and governed. Scholars and students had to adjust their mental models to accommodate new ways of collaborating to achieve learning outcomes, and universities had to change institutional arrangements by introducing new norms, rules and training for lecturers.

This flexibility among university actors (ministries, rectors, deans, department heads and lecturers) helped to ensure student learning outcomes in ways that would have been considered impossible before the crisis. In short, changing mental models and institutional arrangements formed the basis for necessary behavioral shifts within the education service ecosystem. These shifts were moderated by strong motivation and agility, as teachers, 
students and other engaged actors had to address the usual resistance to change to achieve what the UN has described as the most extensive transformation of education ever.

As one indication of the scale of this change, the communication platform Zoom increased its customer base by a factor of more than 30 as university teaching staff adapted their courses, seminars and assessments for online delivery, supported by chat functions and case discussions in virtual breakout rooms. These new teaching modes and the willingness to engage with digital service platforms without professional training confirm the role of motivation in behavior change. Motivation is linked to agility and a willingness to learn new things, adapt to new roles and invest in new value co-creation processes, often without human assistance. For university personnel, this meant learning to record lectures, adjusting assignments for online delivery and developing new forms of assessment, often during what would normally be considered "free time," without any formal planning or a budget. Students also had to be agile in acclimatizing to full-time study from home by learning to use new digital service platforms such as Zoom, Google Meet or Teams, as well as performing ancillary tasks such as upgrading their internet facilities.

In the retail sector, too, the COVID-19 pandemic prompted significant shifts in buying behavior, accelerating the development of remote or contactless customer service resources to safeguard the health of customers and staff. The unprecedented increase in global traffic on retail platforms has surpassed even holiday season peaks. In June 2020, retail websites worldwide generated almost 22 billion visits as compared to 16.07 billion visits in January 2020. The retail industry uses about $8 \%$ of the total workforce in OECD countries, and this is reflected in the scale of government and corporate responses. In Korea, for instance, the government is strengthening supports to enable small businesses to sell online. Large corporations such as Alibaba and Amazon are also improving their online offering, with new services, reduced transaction costs and accelerated delivery and distribution. Retailers such as Uber Eats now offer bike-based delivery services and app-based or online interfaces (OECD, 2020). According to a report from McKinsey and Company (2020), 75\% of consumers in the USA have tried a new store, a new brand or a different way of shopping during the pandemic.

More generally, physical distancing and stay-at-home orders have forced whole consumer segments to shop differently. With this shift in retail behaviors, consumer intent to shop online continues to increase, especially in the essentials and home entertainment categories. The growth of e-commerce, mobile shopping and smart technologies has enabled more rapid adoption of new behaviors among firms and their customers during the crisis. Among the more visible changes, cashiers are protected by glass screens; gloves are provided for customers, and facemasks are required. In the checkout queue, one- or twometer intervals are marked on the floor. Customers have rapidly adapted to these rules, and longer queues have become the accepted norm. To make the process easier, many shops offer options such as click and collect or home delivery. As in the education sector, mental models have changed (e.g. new routines for contactless delivery), as have institutional arrangements (e.g. social distancing rules, new routines for cleaning). Again, these changes foster necessary behavioral shifts that are moderated by strong motivation and agility among service providers and customers as retail actors strive to address the usual resistance to change in habits and routines that are often deeply rooted.

Together, changing mental models and institutional arrangements, the moderating MAR factors, and access to enabling resources such as online search, purchase and payment platforms again highlight the scale of this transformation. To facilitate potential purchasers of new clothes, furniture, kitchen equipment and other goods, retailers have been motivated to develop new home delivery processes, virtual assistants, service robots, and virtual
Drivers of value cocreation transformation 
IJQSS

14,5

"test drives." This new emphasis on online service delivery again demands the agility to adapt to new working hours and unfamiliar tasks, roles and responsibilities. As in the education sector, these shifts in behavior have been almost instantaneous and have met with little or no resistance despite technical difficulties and no immediate overtime provisions.

The above account is based on primary and secondary data collected between March and October 2020. These behavioral responses in the education and retail ecosystems highlight the transformative effects of the COVID-19 pandemic on value co-creation across these and other sectors. Before the pandemic, retailers and educators typically failed to exploit available digital channels to enhance service delivery. The crisis highlighted those disconnects and missed opportunities, prompting changes in mental models and institutional arrangements. The required shifts in behavior and value co-creation were achievable only because key actors were motivated to respond in agile ways to the crisis, embracing change rather than resisting it.

Similar shifts in behavior can be observed in other crises, and we contend that these shifts can also be explained by the framework proposed here. For example, while the financial crisis of 2008-2009 and the Thailand tsunami during Christmas 2004 differed in many respects from the COVID-19 pandemic, the actors involved had to be sufficiently motivated and agile to embrace sudden and fundamental change rather than clinging to established models and institutional arrangements. Clearly, the enablers were different in each case. During the financial crisis, financial services organizations needed government supports in the form of bailouts to keep them afloat. Central banks worldwide coordinated stimulus measures such as liquidity infusion, bond buying and low interest rates, reinventing established mental models to facilitate the necessary behavioral shifts.

While the Thailand tsunami was regional rather than global, its human impacts were felt around the world and rescue and health-care teams and other necessary resources were deployed from many countries with UN support. Again, the mental models of all engaged actors changed immediately and fundamentally in the shift from pre-crisis to crisis behavior, moderated by motivation and agility to overcome resistance to change. In short, while every crisis differs in its detail, the responses of actors in the affected ecosystems follow a similar pattern and are grounded in the same basic mechanisms.

\section{Discussion}

In their review of the marketing and behavioral science literature, White et al. (2019) sought to identify the most effective ways of shifting customer behaviors and concluded that social influence is usually the key. In other words, individuals and groups are most often influenced by the presence, behaviors and expectations of others in contexts involving behavior change (Abrahamse and Steg, 2013). However, this finding relates to normal conditions that do not involve the explicit threats and fear at play in a crisis. As a source of immediate threat, a crisis generates the necessary energy and direction for rapid and significant shifts in behavior that drive the transformation of value co-creation. However, existing mental models will be abandoned only when they fail to account for the situation at hand (Kuhn, 1962). Once this change occurs, it will also affect norms, regulations and laws, given that "institutions are a reflection of evolving mental models" (Denzau and North, 1994, p. 22). As the assumptions and beliefs that guide behavior and interpretation (Dequech, 2013), mental models underpin institutional arrangements through mutual reinforcement (Denzau and North, 1994).

In a crisis, the outcome of any such change is a new understanding of the prevailing reality, prompting new behaviors that would seem difficult or impossible under "normal" circumstances. In the case of value co-creation, behaviors that would otherwise resist 
transformation become less problematic when actors feel included and sufficiently well informed, motivating agile responses amid fear and uncertainty. In the present context, digital service platforms have clearly facilitated collaboration and the free flow of information for rapid decision-making. It is also clear that MAR factors have exerted a more significant influence by making actors less fearful and more willing and able to embrace transformative value co-creation.

In times of crisis, diverse actors - political, professional and social - who might not normally share the same views tend to reach more rapid agreement, so enabling radical change. This radical change alters the relative strength of MAR factors, engendering what Gladwell (2000) characterized as a tipping point - that is, the point at which the unexpected becomes expected, and radical change becomes possible. In the present context, this drives value co-creation transformation such as the replacement of face-to-face teaching by online delivery or the use of digital service platforms for meetings, shopping or medical tests and consultations. Similarly, social distancing means that more people cook at home rather than eating out or sign up with Netflix rather than going to the cinema.

In a crisis, the MAR factors leverage weakened resistance to strengthen motivation and shift behavior as the engaged actors accept the "crisis behavior" and find meaning in it. Rapid change and the transformation of value co-creation in organizations and society have been facilitated by digital service platforms (Edvardsson and Tronvoll, 2020). This enables diverse actors - workers, managers, industries and the general public - to continue to perform essential activities (such as teaching online), resulting in useful outcomes (such as learning). The specific features of each crisis demand different enablers; in the present case, the affordances of digital service platforms have enabled people to stay in touch and to work together to create value, even during a total lockdown. Although the enablers may differ, the framework proposed here seems likely to have explanatory power in relation to behavioral shifts and value co-creation transformation beyond the COVID-19 crisis; this is a matter for further research and in-depth contextualization.

\section{Contribution and further research}

The paper contributes to service research by extending existing conceptualizations of value co-creation in service ecosystems to propose a finer-grained theoretical understanding of the moderating factors and underlying mechanisms of service ecosystem transformation during times of crisis. The proposed framework explains why actors' everyday behaviors shift from pre-crisis to crisis mode in economic, environmental and health crises that affect entire societies, emphasizing shifts in behavior to cope with or respond to the crisis in question. The framework does not address post-crisis or "new normal" behavior or value co-creation, as it is assumed that long-term outcomes are shaped by other factors. As discussed, however, we contend that all crisis responses share certain characteristics, including individual actors' propensity to change their mental models and the moderating factors underlying this change.

The proposed framework also captures how changes in actors' mental models and institutional arrangements drive behavioral shifts that include the transformation of value co-creation and provides a basis for analyzing and explaining such transformations beyond current resource integration accounts (see e.g. Edvardsson et al., 2014; Peters, 2016). In particular, the proposed framework acknowledges the key role of motivation, agility and resistance in changing mental models and associated behaviors that drive the transformation of value co-creation. During the COVID-19 crisis, these changes were facilitated by digital service platforms, but we contend that this framework can also explain behavioral shifts and value co-creation transformation in other crises, referencing as
Drivers of value cocreation transformation 
IJQSS

14,5

10

examples the December 2004 tsunami in Thailand (Telford et al., 2008) and the financial crisis of 2008 (Crotty, 2009). In both of those cases, significant changes in institutional arrangements and the mental models of engaged actors underpinned the behavioral shifts that drove value co-creation transformation in service ecosystems. Although the enablers differ in each case, the observed behavioral shifts and the moderating effects of MAR lend further support to the proposed conceptual framework. In the financial crisis, the most visible enabler was national and international financial support, including substantial liquidity injections into financial markets and new arrangements for financial services organizations. Similarly, the response to the tsunami was enabled by immediate local and national support, followed by international rescue aid and medical services that helped rebuild the destroyed infrastructure.

In the present context, Ostrom et al. (2015) identified the dynamics of value cocreation as a key issue for research - a view echoed by Vargo and Lusch (2016), who stressed the need for conceptual development in this regard (Vargo et al., 2019), as did Brodie and Peters (2020) and Anderson et al. (2013). Existing conceptual frameworks have focused on resource integration and value co-creation in self-adjusting service ecosystems while neglecting the role of behavioral shifts (Edvardsson et al., 2014; Vargo et al., 2019) that drive value co-creation transformation in times of crisis. The framework proposed here supports more fine-grained analysis of that transformation by identifying key factors in the shift from pre-crisis to crisis behavior. This responds to Skålén et al. (2015) call for conceptual development following their empirical analysis of how and why the Arab Spring was co-created. Those events can be characterized as an ecosystem crisis for the countries involved and for society at large. While different in nature, the COVID-19 crisis shares certain general characteristics, including fear, uncertainty, and the widespread use of digital service platforms in pursuit of behavioral change and transformation of value co-creation.

Further conceptual and empirical studies are needed to clarify the critical enablers and drivers of transformation, with particular regard to the enabling role of digital service platforms and the dynamics of routines (Tuominen et al., 2020). As the transformation of value co-creation practices depends on advances in the ostensive and performative understanding of routines (Tuominen et al., 2020), future research should build on routine dynamics theory (Pentland et al., 2012); for example, changes in routines that coordinate collaboration during value co-creation can lead to organizational transformation (Orlikowski, 1996). As Aksoy et al. (2019) suggested, future research should develop mindsets and processes that foster collaboration between academics and practitioners, and this line of inquiry is likely to benefit from direct access to organizational practices.

To test and refine the proposed framework, we recommend that future research should analyze other crises and the processes and outcomes of transformation in financial, environmental and pandemic contexts. This research should encompass short-term responses, long-term institutionalized behavioral shifts and the consequences of transformational value co-creation for individual actors, organizations and society at large. Researchers should also take account of the interdependencies between changing mental models, institutional arrangements and behaviors in driving transformation. Comparison of different crises in terms of the role of behavioral shifts in transforming value co-creation and the short- and long-term consequences may reveal interesting patterns. As one example, it might be useful to compare the dotcom crisis of the 1990s with the financial crisis of 2008-2009. 


\section{References}

Abrahamse, W. and Steg, L. (2013), "Social influence approaches to encourage resource conservation: a Meta-analysis", Global Environmental Change, Vol. 23 No. 6, pp. 1773-1785, doi: 10.1016/j. gloenvcha.2013.07.029.

Aksoy, L., Guilloux, L., Duneigre, H. and Keita, S. (2019), "Viewpoint: service research priorities bridging the academic and practitioner perspectives [article]", Journal of Services Marketing, Vol. 33 No. 5, pp. 626-631, doi: 10.1108/JSM-03-2019-0147.

Anderson, L., Ostrom, A.L., Corus, C., Fisk, R.P., Gallan, A.S., Giraldo, M., Mende, M., Mulder, M., Rayburn, S.W., Rosenbaum, M.S., Shirahada, K. and Williams, J.D. (2013), "Transformative service research: an agenda for the future [article]”, Journal of Business Research, Vol. 66 No. 8, pp. 1203-1210, doi: 10.1016/j.jbusres.2012.08.013.

Baker, S.M., Hill, R.P., Baker, C.N. and Mittelstaedt, J.D. (2015), "Improvisational provisioning in disaster [article]", Journal of Macromarketing, Vol. 35 No. 3, pp. 334-352, doi: 10.1177/ 0276146714550994.

Baker, S.M., Hunt, D.M. and Rittenburg, T.L. (2007), "Consumer vulnerability as a shared experience: tornado recovery process in wright, Wyoming [article]", Journal of Public Policy and Marketing, Spring 2007, Vol. 26 No. 1, pp. 6-19, doi: 10.1509/jppm.26.1.6.

Barile, S., Ciasullo, M.V., Troisi, O. and Sarno, D. (2017), "The role of technology and institutions in tourism service ecosystems: findings from a case study [article]", The Tqm Journal, Vol. 29 No. 6, pp. 811-833, doi: 10.1108/TQM-06-2017-0068.

Baron, J. (2006), Thinking and Deciding, Cambridge University Press, Cambridge.

Barton, L. (2008), Crisis Leadership Now: A Real World Guide to Preparing for Threats, Disaster, Sabotage, and Scandal, McGraw-Hill.

Belenky, M. and Stanton, A. (2000), "Inequality, development, and connected knowing”, in Mezirow, J. (Ed.), Learning as Transformation: critical Perspectives on a Theory in Progress, Jossey-Bass, pp. 71-102.

Belk, R.W., Askegaard, S. and Scott, L. (2012), Research in Consumer Behavior, Vol. 14, 1st ed., Emerald.

Bettencourt, L.A., Lusch, R.F. and Vargo, S.L. (2014), "A service lens on value creation: marketing's role in acheving strategic advantage [article]", California Management Review, Fall 2014, Vol. 57 No. 1, pp. 44-66, doi: 10.1525/cmr.2014.57.1.44.

Borodzicz, E.P. (2005), Risk, Crisis and Security Management, John Wiley and Sons, Ltd, Hoboken.

Bovey, W.H. and Hede, A. (2001), "Resistance to organizational change: the role of cognitive and affective processes", Leadership and Organization Development Journal, Vol. 22 No. 8, pp. 372-382.

Brodie, R.J. and Peters, L.D. (2020), "New directions for service research: refreshing the process of theorizing to increase contribution [article]", Journal of Services Marketing, Vol. 34 No. 3, pp. 415-428, doi: 10.1108/JSM-01-2019-0048.

Broekhuizen, T.L.J., Emrich, O., Gijsenberg, M.J., Broekhuis, M., Donkers, B. and Sloot, L.M. (2019), "Digital platform openness: drivers, dimensions and outcomes", Journal of Business Research, Vol. 122, 2019/07/15, doi: 10.1016/j.jbusres.2019.07.001.

Bundy, J., Pfarrer, M.D., Short, C.E. and Coombs, W.T. (2017), "Crises and crisis management: integration, interpretation, and research development [article]", Journal of Management, Vol. 43 No. 6, pp. 1661-1692, doi: 10.1177/0149206316680030.

Busco, C., Riccaboni, A. and Scapens, R.W. (2006), "Trust for accounting and accounting for trust [article]", Management Accounting Research, Vol. 17 No. 1, pp. 11-41, doi: 10.1016/j. mar.2005.08.001.

Capra, F. and Luisi, P.L. (2014), The Systems View of Life: A Unifying Vision, Cambridge University Press.
Drivers of value cocreation transformation 
IJQSS

14,5

Chreim, S. (2002), "Reducing dissonance: closing the gap between projected and attributed identity", in Moingeon, B. and Soenen, G. (Eds), Corporate and Organizational Identities, Routledge, pp. $75-90$.

Coombs, W.T. (2007), "Protecting organization reputations during a crisis: the development and application of situational crisis communication theory [article]", Corporate Reputation Review, Vol. 10 No. 3, pp. 163-176, Fall 2007, doi: 10.1057/palgrave.crr.1550049.

Crotty, J. (2009), "The financial crisis 2008-2009", Cambridge Journal of Economics, Vol. 33 No. 4, pp. 563-580.

Denzau, A.T. and North, D.C. (1994), "Shared mental models: Ideologies and institutions [article]", Kyklos, Vol. 47 No. 1, p. 3, available at: http://search.ebscohost.com/login.aspx?direct=true\&db= bth\&AN=9405314987\&site=ehost-live

Dequech, D. (2013), "Logics of action, provisioning domains, and institutions: provisioning institutional logics [article]”, Journal of Economic Issues, Vol. 47 No. 1, pp. 95-112, doi: 10.2753/JEI00213624470104.

Dove, R. (2002), Response Ability the Language, Structure, and Culture of the Agile Enterprise, S.1.: WILEY.

Duncan, R. and Zaltman, G. (1977), Strategies for Planned Change, Wiley, New York, NY.

Edvardsson, B., Kleinaltenkamp, M., Tronvoll, B., McHugh, P. and Windahl, C. (2014), "Institutional logics matter when coordinating resource integration [article]", Marketing Theory, Vol. 14 No. 3, pp. 291-309, doi: 10.1177/1470593114534343.

Edvardsson, B. and Tronvoll, B. (2020), "How platforms foster service innovations", Organizational Dynamics, Vol. 49 No. 3, doi: 10.1016/j.orgdyn.2019.04.007.

Edvardsson, B., Tronvoll, B. and Gruber, T. (2011), "Expanding understanding of service exchange and value co creation", Journal of the Academy of Marketing Science, Vol. 39 No. 2, pp. 327-339.

Edwards, J.R. and Lambert, L.S. (2007), "Methods for integrating moderation and mediation: a general analytical framework using moderated path analysis", Psychological Methods, Vol. 12 No. 1, pp. 1-22, available at: $\mathrm{http}: / /$ search.ebscohost.com/login.aspx?direct=true\&db=cmedm\&AN= $17402809 \&$ site $=$ ehost-live

Feldman, M.S. Geiger, D. and Sutcliffe, K.M. (2012), "Routines in hot situations: the role of routines in handling crisis. Academy of management annual meeting".

Fernandes, N. (2020), "Economic effects of coronavirus outbreak (COVID-19) on the world economy)", A. a. SSRN, available at: https://ssrn.com/abstract $=3557504$

Findsrud, R., Tronvoll, B. and Edvardsson, B. (2018), "Motivation: the missing driver for theorizing about resource integration", Marketing Theory, Vol. 18 No. 4, 1470593118764590, doi: 10.1177/ 1470593118764590 .

Gladwell, M. (2000), The Tipping Point: How Little Things Can Make a Big Difference, Little Brown and Company, Boston.

Haaland, H. and Wallevik, H. (2019), "Beyond crisis management? The role of citizen initiatives for global solidarity in humanitarian aid: the case of Lesvos [article]", Third World Quarterly, Vol. 40 No. 10, pp. 1869-1883, doi: 10.1080/01436597.2019.1656060.

Hirschheim, R. (2008), "Some guidelines for the critical reviewing of conceptual papers [editorial]", Journal of the Association for Information Systems, Vol. 9 No. 8, pp. 432-441, available at: http:// search.ebscohost.com/login.aspx?direct=true\&db=buh\&AN=34449407\&site=ehost-live

Hollander, J.A. and Einwohner, R.L. (2004), "Conceptualizing resistance [article]”, Sociological Forum, Vol. 19 No. 4, pp. 533-554, doi: 10.1007/s11206-004-0694-5.

Jaakkola, E. (2020), "Designing conceptual articles: four approaches”, AMS Review, Vol. 10 Nos 1/2, doi: 10.1007/s13162-020-00161-0. 
Jagtap, M. and Deshmukh, A. (2018), "Consumer behavior research: a literature review", International Journal of Management Studies, Vol. 5 Nos 4/9, p. 147, 10/31, doi: 10.18843/ ijms/v5i4(9)/20.

Kappas, A. (2013), "Social regulation of emotion: messy layers", Frontiers in Psychology, Vol. 4, p. 51, doi: $10.3389 /$ fpsyg.2013.00051.

Koskela-Huotari, K., Edvardsson, B., Jonas, J.M., Sörhammar, D. and Witell, L. (2016), "Innovation in service ecosystems - breaking, making, and maintaining institutionalized rules of resource integration [article]", Journal of Business Research, Vol. 69 No. 8, pp. 2964-2971, doi: 10.1016/j. jbusres.2016.02.029.

Kotter, J. (2008), "Shared urgency”, Leadership Excellence, Vol. 25 No. 9, pp. 3-4.

Kuhn, T.S. (1962), "Historical structure of scientific discovery", Science, Vol. 136 No. 3518, pp. 760-764, doi: 10.1126/science.136.3518.760.

Lange, P.A.M.V., Kruglanski, A.W. and Higgins, E.T. (2012), Handbook of Theories of Social Psychology, SAGE.

Lewin, K. (1951), Field Theory in Social Science: selected Theoretical Papers, Greenwood Press.

Littell, J.H. and Girvin, H. (2002), "Stages of change: a critique [article]", Behavior Modification, Vol. 26 No. 2, p. 223, doi: 10.1177/0145445502026002006.

Locke, E.A. (2009), "It's time We brought introspection out of the closet [article]", Perspectives on Psychological Science, Vol. 4 No. 1, pp. 24-25, doi: 10.1111/j.1745-6924.2009.01090.x.

Locke, E.A. and Latham, G.P. (2004), "What should We do about motivation theory? Six recommendations for the twenty-first century [article]", Academy of Management Review, Vol. 29 No. 3, pp. 388-403, doi: 10.5465/AMR.2004.13670974.

Lusch, R.F. and Nambisan, S. (2015), "Service innovation: a service-dominant logic perspective [article]", MIS Quarterly, Vol. 39 No. 1, pp. 155-176.

Lusch, R.F. and Vargo, S.L. (2014), Service-Dominant Logic: Premises, Perspectives, Possibilities, Cambridge University Press.

McKinsey and Company (2020), "Understanding and shaping consumer behavior in the next normal".

Manna, R., Ciasullo, M.V., Cosimato, S. and Palumbo, R. (2018), "Interplaying ecosystems: a mega-level analysis of education and labour ecosystems [article]", The Tqm Journal, Vol. 30 No. 5, pp. 572-588, doi: 10.1108/TQM-11-2017-0139.

Miller, S. (2014), "Social institutions", The Stanford Encyclopedia of Philosophy, available at: https:// plato.stanford.edu/archives/win2014/entries/social-institutions/

Naslund, D. and Kale, R. (2020), "Is agile the latest management fad? A review of success factors of agile transformations", International Journal of Quality and Service Sciences, Vol. 12 No. 4, pp. 489-504, doi: 10.1108/IJQSS-12-2019-0142.

North, D.C. (1990), Institutions, Institutional Change and Economic Performance, Cambridge University Press.

OECD (2020), "Tackling coronavirus (COVID 19) - contributing to a global effort", available at: www. Oecd.org

Orlikowski, W.J. (1996), "Improvising organizational transformation over time: a situated change perspective [article]", Information Systems Research, Vol. 7 No. 1, pp. 63-92, doi: 10.1287/ isre.7.1.63.

Orlov, F. (2017), "Book review. Emotional agility: get unstuck, embrace change, and thrive in work and life by Susan David", Philosophy of Coaching: An International Journal, Vol. 2 No. 1, pp. 52-54, doi: $10.22316 /$ poc/02.1.06.

Ostrom, A.L., Parasuraman, A., Bowen, D.E., Patrício, L. and Voss, C.A. (2015), "Service research priorities in a rapidly changing context [article]", Journal of Service Research, Vol. 18 No. 2, pp. 127-159, doi: 10.1177/1094670515576315.
Drivers of value cocreation transformation

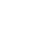


IJQSS

14,5

Pentland, B.T., Feldman, M.S., Becker, M.C. and Liu, P. (2012), "Dynamics of organizational routines: a generative model [article]", Journal of Management Studies, Vol. 49 No. 8, pp. 1484-1508, doi: 10.1111/j.1467-6486.2012.01064.x.

Peters, L.D. (2016), "Heteropathic versus homopathic resource integration and value co-creation in service ecosystems [article]", Journal of Business Research, Vol. 69 No. 8, pp. 2999-3007, doi: 10.1016/j.jbusres.2016.02.033.

Pinder, C.C. (2008), Work Motivation in Organizational Behavior, Psychology Press, doi: 10.4324/ 9781315734606.

Prahalad, C.K. and Bettis, R.A. (1986), "The dominant logic: a new linkage between diversity and performance", Strategic Management Journal, Vol. 7 No. 6, pp. 485-501.

Ramaswamy, V. (2009), "Leading the transformation to co-creation of value [article]", Strategy and Leadership, Vol. 37 No. 2, pp. 32-37, doi: 10.1108/10878570910941208.

Rasoulinezhad, E. (2012), "Evaluation of countries solution against the U.S economics crisis through a multiple attribute decision model (MADM)", Journal of Economics and International Finance, Vol. 4 No. 1, pp. 9-17.

Rigby, D.K., Sutherland, J. and Noble, A. (2018), "Agile at scale: how to go from a few teams to hundreds", Harvard Business Review, pp. 88-96, (May-June).

Roozenbeek, J. and van der Linden, S. (2019), "The fake news game: actively inoculating against the risk of misinformation [article]", Journal of Risk Research, Vol. 22 No. 5, pp. 570-580, doi: 10.1080/ 13669877.2018.1443491.

Sangiorgi, D. (2011), "Transformative services and transformation design", International Journal of Design, Vol. 5 No. 1, pp. 29-40.

Scott, W.R. (2008), Institutions and Organizations: ideas and Interests, Sage Publications, Thousand Oaks, CA.

Senge, P., Kleiner, A., Roberts, C., Ross, R., Roth, G. and Smith, B. (2011), The Dance of Change: The Challenges of Sustaining Momentum in a Learning Organization, Nicholas Brealey Pub.

Shvo, M. Klassen, T.Q. and Mcllraith, S.A. (2020), "Towards the role of theory of mind in explanation".

Siltaloppi, J., Koskela-Huotari, K. and Vargo, S.L. (2016), "Institutional complexity as a driver for Innovation in Service Ecosystems", Service Science, Vol. 8 No. 3, pp. 333-343.

Skålén, P., Aal, K.A. and Edvardsson, B. (2015), "Cocreating the Arab spring: understanding transformation of service systems in contention [article]", Journal of Service Research, Vol. 18 No. 3, pp. 250-264, doi: 10.1177/1094670514559700.

Telford, J., Cosgrave, J. and Houghton, R. (2008), "Joint evaluation of the international response to the Indian ocean tsunami: synthesis report", in Rietjens, S.J.H. and Bollen, M.T.I.B. (Eds), Managing Civil-Military Cooperation: A 24/7 Joint Effort for Stability, Ashgate Publishing Ltd, doi: 10.4324/ 9781315593470.

Tuominen, T., Edvardsson, B. and Reynoso, J. (2020), "Institutional change and routine dynamics in service ecosystems [article]", Journal of Services Marketing, Vol. 34 No. 4, pp. 575-586, doi: 10.1108/JSM-06-2019-0243.

Valaskova, K., Kramarova, K. and Bartosova, V. (2015), "Multi criteria models used in Slovak consumer market for business decision making”, Procedia Economics and Finance, Vol. 26, pp. 174-182, doi: 10.1016/S2212-5671(15)00913-2.

Vargo, S.L. and Lusch, R.F. (2004), "Evolving to a new dominant logic for marketing", Journal of Marketing, Vol. 68 No. 1, pp. 1-17.

Vargo, S.L. and Lusch, R.F. (2008), "Service-dominant logic: continuing the evolution", Journal of the Academy of Marketing Science, Vol. 36 No. 1, pp. 1-10. 
Vargo, S.L. and Lusch, R.F. (2016), "Institutions and axioms: an extension and update of servicedominant logic [article]", Journal of the Academy of Marketing Science, Vol. 44 No. 1, pp. 5-23, doi: 10.1007/s11747-015-0456-3.

Vargo, S.L., Lusch, R.F. and Koskela-Huotari, K. (2019), The SAGE Handbook of Service-Dominant Logic, SAGE Reference.

Drivers of value cocreation transformation

Verhoef, P.C., Broekhuizen, T., Bart, Y., Bhattacharya, A., Qi Dong, J., Fabian, N. and Haenlein, M. (2019), "Digital transformation: a multidisciplinary reflection and research agenda", Journal of Business Research, Vol. 122, 2019/11/02, doi: 10.1016/j.jbusres.2019.09.022.

Vink, J., Edvardsson, B., Wetter-Edman, K. and Tronvoll, B. (2019), "Reshaping mental models enabling innovation through service design [article]", Journal of Service Management, Vol. 30 No. 1, pp. 75-104, doi: 10.1108/JOSM-08-2017-0186.

White, K., Habib, R. and Hardisty, D.J. (2019), "How to SHIFT consumer behaviors to be more sustainable: a literature review and guiding framework [article]", Journal of Marketing, Vol. 83 No. 3, pp. 22-49, doi: 10.1177/0022242919825649.

Williams, L. and Cockburn, A. (2003), "Agile software development: it's about feedback and change [article]”, Computer, Vol. 36 No. 6, p. 39, doi: 10.1109/MC.2003.1204373.

Wooten, L.P. and James, E.H. (2008), "Linking crisis management and leadership competencies: the role of human resource development [article]", Advances in Developing Human Resources, Vol. 10 No. 3, pp. 352-379, doi: 10.1177/1523422308316450.

\section{Corresponding author}

Bo Edvardsson can be contacted at: Bo.Edvardsson@kau.se

For instructions on how to order reprints of this article, please visit our website: 